\title{
Return to neptunism: review article
}

\begin{abstract}
The article tries to revive the traditions of neptunizm. The neptunist Cuvier believed that «the fossil is the key to the past. The past is characterized by a radical break with the present, perhaps it even proceeded according to another physical laws. This is evidenced by the fossils. With the modern action of physical forces, all the deceased remnants decompose. Fossils could have formed during catastrophically rapid burial with reliable isolation from oxygen. The present is the key to the past according to the lawyer Lyell. The past is like the present. It contains an incredible amount of time and years. All processes were going with the same energy as they do now and were not overshadowed by any gigantic disaster. Lyell's statements entered science under the name of the principle of actualism. He gave a paradigmal form not only to the earth sciences, but to all of science, and formed the basis of the evolutionary doctrine. The fundamental dogma of randomness of both natural and all historical processes is the basis of modern scientific ideology. This randomness has no purpose and cannot have. Nevertheless, paradoxically, it predetermines the evolutionary progress of all things. With the appearance of the anthropic principle the teleologism regains its completeness and direction. The anthropic principle is teleological. Since the entire Universe and the biosphere are attuned to human nature, the more such attunement can be expected from earthly nature. There are opportunities for harmonizing human with natural landscapes for health-improving purposes. Nothing was known about the subtlest adjustment of the Universe for humans, or about the incredible complexity of the biosphere even 50-70 years ago. The universe could be explained by evolution and actualism. The discovered incredible complexity of the world brings religion and science closer together. A catastrophic and probably anti-random picture of the planet's history is emerging more and more clear. In this light, the power of science is seen again not in confrontation with religion, but in harmonization with it.
\end{abstract}

Keywords: Neptunism, Great Flood, teleology, actualism, catastrophism, ideology, the anthropic principle, global hydrospheric catastrophes.
Volume 5 Issue I - 202I

Yu N Golubchikov

Lomonosov' Moscow State University, Faculty of Geography, Russia

Correspondence: Yu N Golubchikov, Lomonosov’ Moscow State University, Faculty of Geography, Russia, Email golubchikov@list.ru

Received: December 3I, 2020 | Published: January 14, 202 I

\section{Introdution}

\section{The past according to Cuvier}

Until the mid-19th century, most scientists attributed the decisive role in the formation of the face of the Earth to the catastrophic power of water and were neptunists. The main event in the history of the Earth was considered the Great Flood described in the Bible. The origin of the fossils was associated with it. The most obvious evidence of the flood included granite boulders widely scattered across the northern half of the plains of Europe and North America. Since granites come to the surface in the area of the Baltic and Canadian crystalline shields, it was obvious that they were carried from there by mighty streams of flood waters. They have significantly changed the face of the Earth. Stratigraphy was formed under the influence of the ideas of neptunism and catastrophism. The most prominent representative of catastrophism and neptunism was the founder of comparative anatomy and paleontology, Baron Georges Leopold Cuvier. After examining the fossils of organisms in the Paris Basin, he concluded that life used to be immeasurably richer than today. It was impoverished by great extinctions under the influence of terrible and gigantic catastrophes. In this regard, Cuvier may be named as the first alarmist ecologist, the creator of the first semblance of the «Red Book». By the fossils of extinct life forms Cuvier counted six catastrophic extinctions. The latter was the event of the biblical flood. ${ }^{1}$ According to Cuvier, it is the fossil that opens a new approach to history. With Cuvier, the nineteenth century begins the search for new sciences and methods of restoring past worlds, destroyed and fragmented by time. ${ }^{2}$

According to Cuvier «the fossil is the key to the past». Modern processes of rapid decay of organisms do not allow to accumulate any fossils. Meanwhile, most of the fossils are represented by invertebrates that did not have hard skeletal forms - coelenterates (various jellyfish and polyps), annelids and flat worms, insects, marine invertebrates without a hard skeleton (starfish, jellyfish, brachiopods and shellfish). They usually do not differ from modern forms. These days, they decay especially quickly, literally in a few hours. All living beings who have died today are decomposing and do not have time to turn into stone. The dead fish floats to the surface of the water and begins to decompose. The corpses of dead animals on land are eaten by others or decompose quickly. The soft parts disappear in days, the hard parts in years and decades. Microbes, worms, insects leave no time for organisms to petrify. If not for them, the earth and the bottom of the reservoirs would be covered with multi-meter thick shells, bones and teeth. Without destroying the old, the new does not arise. Almost nothing will remain from the life of our day in the future, since everything that has perished in it decays. Thus, Cuvier concludes that there is a fundamental break between the present and the past. It is impossible to state how much time and years passed in that past. Geological layers serve as its reflection, but they are torn, blurred and defragmented. It is not known how long it takes to form a particular layer. We can assume, they formed catastrophically quickly, burying the remains of the creatures that lived then.

Cuvier pointed out that everything that can be found elsewhere in the form of fossils in the Far North is presented in fresh frozen form, and especially drew attention to frozen mammoth carcasses. Cuvier believed that if the mammoths did not freeze immediately after they were killed, rotting would decompose them. «One and the same process destroyed them and froze the country in which they lived. This incident happened suddenly, instantly, without any gradualness». ${ }^{1}$ 
Cuvier can also be promoted to the founders of permafrost science, though modern permafrost scientists do not consider him as one of them. Unlike Cuvier, they regard the formation of permafrost, the accumulation of underground ice deposits and the extinction of mammoths as three independent, sluggish processes. Cuvier ${ }^{1}$ associated evidence of catastrophes and revolutions in the history of the Earth with marine fossils found on mountain tops. Cuvier believed that qualitatively different extraordinary forces with much more powerful energetics and speeds were operating in that times, possibly carried out according to different laws. Modern processes, even if they operate for millions of years, are still insufficient for the emergence of the Alps or the Caucasus. Although it could be the same volcanic eruptions or earthquakes, only much more powerful. Thus, Cuvier is considered the founder of catastrophism. Modern science gives no reason to assert that the forces that are inactive today could not manifest themselves in the past, or that the forces acting in the past are correctly understood by us in the present. The same gigantic deposits of fossil organisms continue to testify to the action of extraordinary forces in the history of the Earth. There are many examples of very rapid production of oil or anthracite in laboratory conditions, but no one has yet been able to reproduce the process of fossilization of multicellular organisms.

Why, then, do fossils often overwhelm the layers of bygone geological eras? Pieces of petrified trees and petrified leaves are found almost everywhere. For them to remain fossilized, it is necessary to allow their sudden burial while still alive by a layer of sediment. If we divide the thickness of the sedimentary layer by the time of its formation on a geochronological scale (millimeters over hundreds of years), then no remnants of organisms should be preserved at all. Nevertheless, each year brings the discovery of more and more millions of fossilized remains of animals and plants, which form huge «cemeteries». Nevertheless many, if not most of the fossils were later redeposited, slowly destroyed or annihilated by subsequent disasters.

\section{The past according to lyell}

Very few people rejected the validity of the Bible's Flood account. The Geological Society of London gave strong support to these unusual views. Lawyers, parliamentarians, merchants, doctors, clerks, officers were among its members, there were not only geologists. They belonged to the Whig anti-monarchist party, the same one that subsequently launched in England the Chartist movement for a significant restriction of monarchical power. ${ }^{3}$ In April 1848, the famous Chartists roused the people to an armed uprising in England for the overthrow of the king. The uprising was prevented by the decisive actions of the winner of Napoleon at Waterloo, the Duke of Wellington, but the revolutionary events covered France, Germany, Austria-Hungary, Italy that year. In 1830, a 33-year-old member of the Geological Society, lawyer Charles Lyell, begins year after year to publish three thick volumes, it would seem, far from a field of jurisprudence, entitled «Principles of geology, being an attempt to explain the former changes of the Earth's surface, by reference to causes now in operation». Lyell carefully measured the rate of accumulation of modern sediments in calm conditions of stagnant bodies of water. It amounted to millimeters or a few centimeters per year. Then he divided the thickness of sedimentary rock strata known to him by this rate and received, for those times, huge ages of the strata. If $300 \mathrm{~m}$ were accumulated per centimeter per year, then we get the age of the strata at 30 thousand years. Lyell began to prove with advocate's pathos that all geological processes and phenomena in the past were the same as they are now. There was no any gigantic disaster, and if catastrophes in the history of the Earth happened, then as ordinary geological and paleontological events. Everything went slowly and gradually with the same energy as now. These statements entered science under the name of the principle of actualism (from the Latin actualis - «real»), or uniformitarianism (from the English «uniformity» and «inviolability»). His motto - «the present is the key to the past» has given a paradigm form not only to the earth sciences, but to all of science.

Before Lyell, the present is characterized by a radical break with the past, it does not allow to understand it. After Lyell, the past is like the present. It contains an incredible amount of time and years. During these epochs and periods, rock strata accumulated extremely slowly. In special facies conditions, which contributed to the isolation from oxygen, preserved the remains of organisms, which today appear as fossils. These extremely rare events over many millions of years are now imprinted in the strata of sedimentary rocks. The weak link in Lyell's scientific principle was the appearance of new species with the extinction of old ones. He attributed them to mysterious and supernatural reasons. The 27-year-old priest Charles Darwin helped to Lyell. Lyell rejected global catastrophes in the history of the Earth and man. Darwin linked the reason for the disappearance of some species and the appearance of others not with catastrophic extinctions, but with the slow action of the forces of natural selection. Darwin strongly supported Lyell's uniformitarian views and even published several articles on the rationale for the ancient glaciation of the British Isles and South America. ${ }^{5}$ In turn, Lyell, in the development of the evolutionary teachings of Darwin, published the book « Geological Evidences of the Antiquity of Man». The doctrine of actualism historically and logically preceded Darwin's evolutionary theory. It was Charles Lyell who gave those necessary lengths of time that Charles Darwin needed for his interspecies transitions. No one has seen the appearance of a new species anywhere today, but extinctions are visible everywhere. Therefore, no one will believe the assertion of the type that a rat originated from a flea, but if you say that over millions of years, then they will believe. So, the lawyer Lyell gave the necessary time scale to the Anglican priest Charles Darwin to build his evolutionary doctrine. By long periods of time it explains the transformation of inanimate matter into the simplest living organisms, the emergence of some biological species from others. Until, finally, one or more pairs of monkeys were gifted with human offspring so unexpected for them.

The teachings of the two Charles swept the scientific world with remarkable speed. Every researcher knows what incredible work it takes to gain credibility among colleagues. So, how could a lawyer among geologists and a priest among biologists gain it? As stated by the British historian of geological science Charles Gillispie, ${ }^{3}$ the real purpose of spreading evolutionary teachings was the creation of alternative theories to the biblical about the appearance of the Earth and man. This opened the opportunity to question the entire Christian worldview, discredit the structure of Christian states associated with it, and, ultimately, take possession of their capital, fortunes and estates. This means killing all bad people, otherwise there are very few good people, says a five-year-old girl from A. Platonov's novel «The Foundation Pit». Her wise words seem to be the key to understanding the entire world history of the 20th and 21 st centuries. Since the middle of the $19^{\text {th }}$ century, the idea that every new scientific achievement crushes certain religious dogmas has been strengthened in public opinion. The confrontation between religion and science begins. Biblical concepts and teleology are being eradicated from the new worldview. V.I. Vernadsky wrote: «Geological sciences in the 19th century forced both religion and philosophy by the power of 
logic and life applications to bow before the scientific fact and remake their constructions». ${ }^{6}$ Only in science, ideology determines what is a fact and what is not. ${ }^{7}$

\section{The overthrow of catastrophism}

Lyell especially attacked the ideas of the Great Flood contained in the traditions of the peoples of the whole world. In private statements and correspondence, he did not hide that his «Principles of Geology» were aimed at «drowning» his enemies, whom he identified as diluvialists (neptunists), theological sophists and «physicotheologists». ${ }^{4}$ Criticism of the biblical story began with the events of the Great Flood as the key one in the Bible. And it is also necessary to restore the sacred picture with the recovery of the truth about this global hydrospheric catastrophe. The formation of landforms and sediments attributed to deluge, since then began to be explained at first by the spread from the ice drifting in the sea. Then appeared a paradigm of actions of slowly advancing and retreating huge ice sheets. Since then, the importance of water in shaping the appearance of the earth's land has been steadily narrowing, up to the recognition of its leading role only in the formation of valley and coastal complexes. Landforms previously attributed to water activity began to be interpreted as glacial, nivational, and denudational. If it is said about hydrospheric disasters, then they are associated with the breakthrough of glacial waters. The term catastrophism is still used with a negative connotation. The attitude to it in the Soviet scientific literature was as to something almost criminal. The Great Soviet Encyclopedia quoted the words of F. Engels: «Cuvier's theory of the revolutions endured by the earth was revolutionary in words and reactionary in deeds». The following was the verdict of I.V. Stalin from the work «Anarchism or Socialism?». «It clear that there is nothing in common between Cuvier's cataclysms and Marx's dialectical method. ${ }^{8}$ It is unlikely that after such words there would be anyone willing to join the ranks of catastrophists.

«For many decades in the USSR the very existence of the Flood was viewed as a fairy tale, almost as a kind of religious propaganda about the catastrophe, which, according to Soviet ideology and, accordingly, (!) The science of that time, simply could not exist».? The doctrine of ice sheets appeared instead of the Flood legend. Lyell attacked especially the ideas of the Great Flood contained in the traditions of the peoples of the whole world. The formation of landforms and sediments attributed to deluge began to be explained by the action of slowly advancing and retreating huge ice sheets. This happened also because in the period attributed to the ice age, a man appeared. And evolutionary doctrine cannot imagine such an event without slow and gradual adaptations of monkeys to changes in the natural environment, which forced them to turn to work. What if there were no man apes? Let us say, the closest relatives of humans would be cats. Then it would be proved that with the onset of the ice age, some humaniform cats caught mice for themselves to sew fur coats from their skins. Those that did not sew died out, and those that sewed became people. So, depending on the interpretation of Quaternary deformations, we get a different picture of the universe: or there was a glacier and then we came from Africa and descended from monkeys, or there was no glacier and then, perhaps, our ancestors themselves once flourished here.

\section{Replacing a goal with chance}

The science of goals is called teleology (thelos - in Greek «goal»). It is condemned by social scientists as a return to «medieval obscurantism.» Although, in a latent form, teleology is the essence of all teachings about the progressive development of mankind, especially Soviet ideology with the idea of building a bright communist future. The very principle of consistency is built on goalsetting, and, therefore, is teleological. All organisms are teleological. L.S. Berg brilliantly demonstrated that science for a long time followed the teleological path of the formation of the doctrine of the goal. ${ }^{10}$ Aristotle said that works of nature originate in the same way as works of art. Both must have not only the formal features of unity, integrity and completeness, but also be purposeful for something reasonable. But natural organisms are more integral, more beautiful and more essence than works of art, because the purpose in them is present in the organism itself. The soul of an animal, for example, is present in this animal itself and is inseparable from it. This soul is the entelechy and purpose that gives structural integrity to the body. But the «soul» of a work of art is outside it. It is eidos and it is the goal of the work. ${ }^{11}$ Not only living beings, but all cosmic systems have an internal teleology (entelechy). The whole Universe has it. Aristotle's concept of the universe is deeply biological.

In modern scientific phraseology it is assumed that objects of natural origin self-organize, and everything that is created by a person is organized by him. Both occur during the transition from chaos to order due to a certain non-equilibrium. ${ }^{12}$ The ideas of Aristotle and Plato were developed by L.S. Berg in his concept of nomogenesis (Greek nomos - «law»), according to which the evolution of living systems is directed along a certain «channel» by a certain goal. In this, nomogenesis differed from Darwinian evolutionary doctrine based on chance. «The search for ultimate goals is the primary and most important task of the study of nature», - L.S. Berg repeated after Aristotle. ${ }^{10}$ The inquisitive mind sees everywhere that inanimate matter serves living, and that, in turn, serves human. We do not know and will hardly be able to explain why the ozone layer has isolated in the atmosphere, which serves as a barrier between the deadly solar radiation and planetary waters, but we clearly understand why: to protect life. During the entire time of its existence, not a single catastrophe that destroyed it occurred, although any good comet could burn it. This means that no such event has occurred in the history of the ozone layer. The introduction of the teleological principle into cognition makes it possible to explain the gigantic volumes of facts. "And this is most necessary in history, where no event can exist without a goal $»^{13}$ However, such a concept as «goal» has been thrown overboard by modern science. The basis of modern scientific ideology is the fundamental dogma of the chance of both natural and all historical processes. This chance has no purpose and cannot have. Nevertheless, paradoxically, this randomness predetermines the evolutionary progress of all that exists.

According to the outstanding Russian philosopher Viktor Aksyuchits: "The image of the universe that science is so proud of («the world is an automaton», the universe is a wound-up clock) is an image of hell ... The endless circulation of matter, existence according to frozen unchanging «laws» are devoid of purpose, and hence meaning, and senseless vegetation is one of the forms of non-being». ${ }^{14}$ Things like light, water, or oxygen do not come from anything. Water does not come from vodka and over time it can only deteriorate, and not evolve into a purer, crystalline, healing one. Likewise, the light also dims over time or somehow dries up. The bearer of spiritual light - man - also appears at once in all his splendor and diversity with all his rich languages, which are also subject to depletion. Compare in this regard the Church Slavonic and Russian languages, especially its obscene degeneration. Having once worn a much larger brain volume (Neanderthal), he is also subject to the processes of degeneration and decay. Although people of the highest destiny have always remained and live among us. Ultimately, everything about fundamental genesis 
lies in the realm of science fiction. No matter how deeply we study the morphology of the organism, we cannot say anything about its conception. No matter how we comprehend geomorphology, we will not be able to judge by it about the origin of the Earth. Depending on the answers to questions about the principles and goals of our world, we get not only a different picture of the universe, but also get two diametrically opposite ontologies. Either we are a chaotic grain of sand on the edge of a soulless evolving universe, or the entire universe is built for us. From these answers, goes not only morality, but also the very happiness of humanity.

\section{The anthropic principle}

Even in the Middle Ages, man felt himself at the center of the universe. The stars revolved, the moon shone, the sun rose and set for his sake. All cosmology was teleological and anthropocentric. By the middle of the 20th century not a trace remained of that worldview. If life is removed from a modern physics textbook, then nothing will change in it. Physics needs neither life, nor the biosphere, and, moreover, humanity. If they are amputated, then nothing will change in the modern physical picture of the world. The emergence of the biosphere and mankind began to be interpreted as the result of the action of very long, but absolutely blind forces; and in the universe itself, they began to see neither greatness, nor beauty, nor meaning, nor purpose. «Increasing the world to extreme dimensions, the new scientific worldview at the same time relegated man with all his interests and achievements - reduced all the phenomena of life - to the position of an insignificant detail in space. ${ }^{15}$ The biosphere was not mentioned in the known geotectonic concepts for many years. ${ }^{16}$ Although V.I. Vernadsky considered the granite shell of the Earth as traces of bygone biospheres. ${ }^{17}$ Will not only such traces remain from our biosphere? The views of the great thinkers of the past about the biological or teleological nature of the universe seemed to have been finally overcome. Suddenly, they began to revive again from the 1970s. Then it was revealed that the most important laws of physics are set by 9 fundamental constants such as the gravitational constant or the electron charge. By the end of the 1980s already indicated 30 such constants, then 70 . Now there are 200 of them. ${ }^{18}$

Each of these constants is limited to very narrow values, looks random, not related to others, it seemed, could have different values. Nevertheless, each time it turned out that not only these constants, but also their ratios are critically important for the existence of our world. Not a man with the Earth is adjusted to them, but they themselves are filigree tuned to a person on Earth. ${ }^{19}$ Even a small mental variation of one of the constants leads to the loss of stability of the entire Universe. It will become not some other, suitable, say, for other matter, but, in principle, losing its physical meaning. The proton is 1836 times heavier than the electron. If this ratio becomes slightly different, in the 28th unit after the decimal point, then either the electron will fall on the proton and the whole world will turn into a desert of hydrogen, or, on the contrary, the electron will break away from the proton and then everything will fall apart even more, which cannot be imagined. ${ }^{19}$ If the slightest change in the numerical values of one of the constants of the Universe occurs, then it will mean «the end of the world», i.e. the entire material universe with all its countless galaxies. The idea of the Pythagoreans that «numbers rule the world» and create its order is again relevant. The Greek root «cosm» itself means «order», and the word «cosmos» is translated as the universe, arranged in a strict order, hence the word «cosmetics». Order is directly opposite to chaos and can only turn into it, but in no way come from chaos. It became possible to exclaim: «Here is a man. What should the universe be like?!» «Alfred Wallace noted «Man ... could develop here on Earth only in the presence of all this monstrously vast material Universe that we see around us. ${ }^{20}{ }^{»}$ K.E. Tsiolkovsky also considered the entire cosmos as that which determines our life: «It is difficult to assume that any part of it would not have any influence on us sooner or later. ${ }^{21}$

It turns out that for such a small Earth to revolve around its axis in its orbit, the existence of a huge Universe is necessary. All its stars are important and necessary for us. The star dome has become immeasurably closer and more human-sized. Maybe the foremother of astronomy, astrology, so violently trampled by astronomers, is right in some way. It is hypothesized that the influence of distant stars on us goes through unknown energyless fields. The speed of their propagation can exceed the speed of light by tens of thousands of times due to the exit into additional dimensions and subsequent return to our dimensions. Academic physics «does not see» them, since it is focused only on energy (material) fields. Meanwhile, the physical processes themselves are controlled by some non-forceful, energyless methods that are not clear to us, which are called the laws of nature..$^{22}$ Their goals, perhaps, should be sought in the non-material world. It seems that teleologism, long overcome, is regaining its fullness and direction. A certain plan of the universe (nomogenesis) is revealed again. Perhaps the anthropic principle is that entelechy that predetermines the structure of matter and impels it. It not only admits the possibility of the emergence of life, but determines it, revives Aristotelian biology.

\section{Geotectonic goals}

It is found that life also predetermined and ordered the face of the Earth, transforming it for the benefit of its preservation and prosperity. This is the main feature of the geotectonic development of the unique bioplanet Earth. ${ }^{16}$ The lower layers of the atmosphere are heated on average by $0.1-0.2^{\circ} \mathrm{C}$ per year because of the penetration of the Earth's internal heat outward. Academician A.A. Grigoriev drew attention, ${ }^{23}$ that much more solar energy would be spent on heating the lithosphere outside without this insignificant excess of endogenous heat, to the detriment of warming up the lower layers of the atmosphere. There is an increased loss of endogenous heat in mountain areas to ensure that the heat flux from the earth's interior does not exceed its insignificant values. It happens for two reasons: first, the earth's crust comes into contact with cold and rarefied layers of the atmosphere in the mountains, they take away a lot of excess heat from the earth's surface. ${ }^{23}$ The second reason is associated with the increased volcanic and tectonic activity of the mountains. As a result, the Earth's crust is intensively destroyed and a cooling front spreads into it along the faults. ${ }^{24}$ Maybe this is the purpose of geotectonic processes? According to the calculations of Friedrich Ratzel ${ }^{25}$ the volume of the World Ocean is 13 times greater than the volume of the land that rises above its level. To swallow up all the earth's land, the ocean needs to increase its volume by only $7.7 \%$. If the ocean rises by $1000 \mathrm{~m}$, then the land surface will immediately shrink by $80 \%$. Then the palette of natural zoning and biodiversity will become impoverished on Earth, and, for example, deserts will disappear. If the earth's land rises by $1000 \mathrm{~m}$, then its surface will increase by only $30 \%,{ }^{25}$ and organic life will be under the threat of global desertification. For the Earth to have dry land, mountains must rise again and again, and the ocean floor must constantly sink. It turns out that tectonic and volcanic forces are important and necessary for life, it is their purpose. «There would be no heaven without the firmament.

\section{Anthropness of the biosphere}

In the light of the anthropic principle, a human was shown not as a simple inhabitant of the planet, but as its owner. Having entered the 
land, he met all the conditions for a comfortable existence. For the benefits and elevation of human, magnificent forests spread, deposits of coal and hydrocarbons accumulated. Myriads of invertebrates had to die and overwhelm the strata with their fossils so that the earth was covered with fertile soil. «You, poor man, do not tread on the floor of your house, but you walk on the roof of your house, and only a multitude of floods gave your house its present appearance,» Johann Herder wisely taught. ${ }^{26}$ Many attempts have been made to subvert the anthropic principle. It was said about the multitude of universes, about the conventionality of the principle that the modality of duty is not correct in science. But the anthropic principle itself is increasingly penetrating the sphere of general scientific (including humanitarian) culture and methodology. Its appearance contributes to the naturalhumanitarian unity of all science. The most perspicacious minds guessed about the anthropic principle long before its appearance. Ehe anthropic principle is called God's providence for man in religious language. Science with the anthropic principle again approaches religious knowledge, between which by the middle of the twentieth century an almost insurmountable wall was formed. ${ }^{27}$

Too many «happy accidents» had to coincide in their unique combination for the biosphere to exist for several billion years. This means that they have not changed significantly in the history of the planet. How could the biosphere have existed for so long with the relative constancy of its main characteristics? After all, any invasion of an average comet could already destroy this wonderful spaceship. And why does the realization of the anthropic principle need so many billions of years? Perhaps we misjudge ages?

The principle of actualism considers it indisputable that the rates observed today (from the accumulation of geological strata to radioactive decays) have always been so. It has been established that the current decay rates of radioactive elements do not change at any temperature, pressure and other physical and chemical external influences. It was decided that this has always been the case, that radioactive decay can be viewed as a kind of ultra-stable clock, the rate of which is determined only by the decay constant. The development of experimental techniques and the expansion of the possibilities of external influences on the rate of radioactive decay showed that extreme influences on the electron shell of an atom can lead to a change in the rate of various types of half-life. ${ }^{28}$ In addition, the initial rate of the observed processes is almost never equal to the final rate. Under natural conditions, the longer the duration of a process, the less intensity it takes, and vice versa. For example, a heated kettle decreases its temperature at first quickly, then more and more slowly and slowly. If you measure its temperature an hour after boiling, then within 5 minutes it can turn out to be very slowly decreasing, almost constant. By extrapolating the obtained cooling rate into the past, we find that it began a long time ago. Also, by our time, the speed of all processes, including nuclear, chemical, radioactive, could slow down. ${ }^{29}$ The history of the Earth is often likened to a calendar year or represented as 24 hours. January 1 or midnight is taken as the date of birth of life. Then the planet was lifeless and cold. Between 5 and 6 o'clock in the morning, at the daily clock, the first microorganisms appear, and at $1 \mathrm{pm}$ free oxygen appears. Modern people appear on this calendar only half a minute before midnight at the daily clock. The entire history of mankind is enclosed in this half a minute. Was it necessary for such a grandiose task to pile up such huge quantities of years? Everything probably went faster and more expediently, in full accordance with the anthropic principle. Is it not with the first rays of the Sun lit for it that humanity meets the morning dawn of its universe?

\section{Anthropic nature of landscapes and its significance in a pandemic}

Since the entire Universe and the biosphere are attuned to humans, the more such attunement can be expected from earthly nature. A. L. Chizhevsky asserted that «Each atom of living matter is in constant continuous relationship with the vibrations of the atoms of the environment - nature, each atom of the living resonates to the corresponding vibrations of the atoms of nature»..$^{30}$ This opens opportunities for harmonizing the body with natural landscapes for the purpose of healing. That is why doctors used to say to a sick person: «Give up everything and go to nature.» «It is from Nature that you can learn how to preserve yourself and improve the conditions for Life on Earth». ${ }^{31}$ It can be assumed that the importance of natural healing increases during various pandemics. V.P. Kaznacheev wrote that the biosphere has the property of sanitizing from pathogenic factors and viruses. Meanwhile man, destroying the biosphere, deprives it of its sanitizing functions. Therefore, it is no coincidence that endemics, pandemics, and tumor processes occur. They should not be reduced to «only that biochemistry, infections, toxicants, radiation that dominate today, this process is deeper». ${ }^{32,10}$

We associate the sudden COVID-19 pandemic with abnormally low solar activity and its depletion in ultraviolet light. ${ }^{33}$ In 2020 , it turned out to be a record low for all 200 years of instrumental observations. ${ }^{34}$ Indicators of the state of many parts of the planetary system were characterized in 2020 by maximum deviations from the norm..$^{35}$

Reduced solar activity is associated with a decrease in the flow of ultraviolet radiation, which disinfects the atmosphere. This creates conditions both for the multiplication of viruses and for reducing the immunity of people. As a result - the emergence of a global viral epidemic, amplified by a decrease in the effectiveness of antibiotics. At the same time, reports are emerging of an unprecedented depletion of the ozone layer in 2020, despite the decline in air travel that depletes the ozone layer. With the destruction of ozone, an increase in the flux of biologically active ultraviolet radiation should be expected ${ }^{36}$ But since the area of the ozone hole is located over the Arctic and Antarctic, then people are more likely to suffer from a decrease in the intensity of the ultraviolet flux due to minimal solar activity. It is better to compensate for the deficiency of ultraviolet radiation with the greatest possible exposure to the sun in solitude among the trees. Therefore, the coronavirus pandemic enhances the importance of dacha recreation, secluded landscapes, therapeutic walks, local history, and rural tourism. The Swiss physician Philip von Hohenheim Paracelsus, who lived in the 16th century, argued that plants purify the atmosphere by taking in everything exhaled by animals and people. Plants adopt diseases from humans and animals in the same way. All harmful plants absorb into themselves, converting them into healing oxygen. Paracelsus's thoughts began to find confirmation with the discovery of phytoncides and terpenes. Italian botanists associate the low incidence of coronavirus in the southern regions of Italy, compared to the northern ones, with their greater forest cover. In this they see a positive effect on the human immune system of inhalation of volatile compounds released by trees, and recommend «forest bathing» and the practice of visiting forests in the fight against coronavirus. ${ }^{37}$ Probably one should avoid various types of tectonic faults in landscape-therapeutic walks. They contribute to a change in the composition of soil, water, air, radioactivity, and oxygen deficiency. The processes of transformation and dispersal of microorganisms, mutations of microbes, and their spread occur more intensively near the faults. ${ }^{38}$ 


\section{Religion and science rapprochement}

In the light of the anthropic principle, the biosphere appeared as a single gigantic, precisely adjusted eye. The eye could arise only immediately and entirely, before all its constituent parts. Each of the eye particles separately does not perceive any light quantum. Every smaller isolated part of it is doomed to perish, and the eye itself may die without it. The evolution of the eye can be represented as the development of an organism from an embryo, but not from the components of the eye itself. The same can be traced in the entire universe. It, apparently, appears immediately and entirely with all its anthropic properties too. Even 50-70 years ago, nothing was known about the subtlest adjustment of the Universe for humans, or about the incredible complexity of the biosphere. It was quite possible to admit the spontaneous and accidental formation of such structures. The universe could be explained by evolution and actualism. The incredible complexity of the world that has opened brings religion and science closer together. A catastrophic and probably anti-random picture of the planet's history is emerging more and more clearly. The universe ceases to be understood from the point of view of reductionism, empiricism, actualism, atheism, positivism, mechanistic materialism. Reinterpreting them in line with new hypotheses (in particular, the neo-catastrophic model of the universe) can serve as a new, more precisely «well-forgotten old» compass not only for practical, but also for scientific and philosophical search. The power of science again appears not in opposition to religion, but in harmonization with it.

\section{Acknowledgments}

I express my gratitude to the editor of IJH Shirisha for her insistence on preparing and submitting this article.

\section{Conflicts of interest}

The author declares there is no conflict of interest.

\section{References}

1. Cuvier J. About upheavals or changes on the surface of the globe in natural and historical terms. Odessa, 1840. p. 225.

2. Attanucci T. The Restorative Poetics of a Geological Age. Stifter, Viollet-le-Duc, and the Aesthetic Practices of Geohistoricism. Series: Paradigms, 11. De Gruyter, 2020. p. 228.

3. Gillispie CC. Genesis and Geology. The Impact of Scientific Discoveries upon Religious Beliefs in the Decades before Darvin. New York, Haprer Torchibooks, 1959. p. 306.

4. Cosslett T. Science and Religion in the $19^{\text {th }}$ Century. (Cambridge English Prose Texts). Cambridge University Press, 1984. p. 256.

5. Shatsky NS, Yanshin AL. Portraits of geologists. Moscow: Nauka, 1986. p. 304.

6. Vernadsky VI. Space and time in inanimate and living nature. Philosophical thoughts of a naturalist. M Nauka, 1988. p. 210-385.

7. Gorkin AP. On the relativism of economic geography (objective and subjective aspects). Theory of socio-economic geography: current state and development prospects /. In: G Druzhinina et al., editors. Materials of the International Scientific Conference (Rostov-on-Don, May 4-8, 2010). - Rostov-n / D, 2010. p. 32-36.

8. Catastrophe theory (catastrophism) // Great Soviet Encyclopedia. M TSE, 1953. p. 365-366.

9. Grigoriev $\mathrm{Al} \mathrm{A}$. The world of geography in the mirror of art. $\mathrm{SPb}$ : Asterion, 2019. p. 238.
10. Berg LS. Works on the theory of evolution. Moscow: Nauka, 1977. p. 388

11. Losev AF. History of ancient aesthetics. Aristotle and the late classics. History of Ancient Aesthetics. Volume IV, M Art, 1975. . 672.

12. Smirnova NL. On the identity of the organization and self-organization of the local order. System Planet Earth (nontraditional questions of geology). M Materials. RPO «Harmony of the structure of the Earth and planets. M LIBROKOM. 2008. p. 47-58.

13. Gogol NV. Articles. Selected works. Volume VI. - M Fiction, 1986. p. 544.

14. Aksyuchits VV. The death of the gods of naturalism. The limits of science and the fiasco of the scientific worldview. M., Berlin: DirectMedia. 2018. p. 293.

15. Vernadsky VI. Problems of biogeochemistry // Proceedings of the Biogeochemical laboratory, T. XVI. Moscow: Nauka, 1980. p.320.

16. Mertsalov IM. Crisis of "theories» of deep processes of the Earth, causes and way of overcoming. System Planet Earth (non-traditional issues of geology). M Materials. RPO «Harmony of the structure of the Earth and planets. M LIBROKOM. 2008. p. 304-307.

17. Vernadsky VI. The chemical structure of the Earth's biosphere and its surroundings. Moscow: Nauka, 1965. p. 374.

18. Lanza R, Berman B. Biocentrism. How life creates the universe. SPb: Peter, 2015. p. 224.

19. Lewis GF, Barnes LA. A Fortunate Universe: Life in a Finely Tuned Cosmos. Cambridge: Cambridge University Press, 2016. p. 373.

20. Wallace AR. The Place of Man in the Universe. L Lakiera. SPb. 1904. p. 292.

21. Tsiolkovsky KE. The cause of space. Tsiolkovsky K.E. Essays on the Universe. Kaluga: Golden Alley, 2001 p. 384.

22. Vasiliev SA. Natural philosophy of an impasse in understanding the fundamental phenomena of quantum physics and a step towards a way out of it (including the problem of the entangled state and wave-particle dualism). 120 years since the birth and 75 years since the death of Yuri Vasilyevich Kondratyuk (Alexander Ignatievich Shargei) (1897-1942). M: LENAND, 2017. p. 23-57.

23. Grigoriev AA. Regularities of the structure and development of the geographic environment. M Mysl. 1966. p. 384.

24. Romashov AN. Planet Earth: Tectonophysics and Evolution. M Editorial URSS, 2003. p. 264.

25. Ratsel F. Land and Life. Comparative Geography. In 2 volumes. SPb. 1905;1:736.

26. Herder IG Ideas for the philosophy of the history of mankind. Moscow: Nauka, 1977. p. 704

27. Golubchikov Yu N. Essays on human geography. M. ANO Dialogue of Cultures. 2020. p. 240

28. Panchelyuga VA, Panchelyuga MS, Serov O Yu. Preliminary results of the study of the relationship between intraday periods (2-24 hours) in time series of fluctuations in the rate of alpha decay with natural oscillations of the Earth. $120^{\text {th }}$ anniversary of the birth and $75^{\text {th }}$ anniversary of the death of Yuri Vasilyevich Kondratyuk (Alexander Ignatievich Shargei) (1897-1942). M LENAND. 2017. p. 23-57.

29. Veinik AI. Thermodynamics of real processes. Minsk: Science and technology, 1991. p.576.

30. Chizhevsky AL. Cradle of Life and Pulses of the Universe // Russian Cosmism: Antolgia of Philosophical Thought. / Comp. and foreword. To the texts by SG Semenov et al., editors. Note. A.G. Gacheva. M Pedagogika-press, 1993. p. 317-327. 
31. Mertsalov IM. The most ancient natural law of the development of life and the present // System "Planet Earth»: 200 years since the death of Mikhail Bogdanovich Barclay de Tolly (1761-1818): collection of articles. Art. / ed.-comp. A.E. Fedorov. - M .: URSS: LENAND, 2018. p. 332-338.

32. Kaznacheev VP. Interpenetration (dissymmetry) of parallel worlds of space-time (Einstein-Minkowski) and energy-time (Kozyrev) (Thoughts to a new generation). Physics of consciousness and life, cosmology and astrophysika. 2015;3:5-14.

33. Golubchikov Yu N. The solar component of the cornavirus pandemic // Socio-economic geography. Bulletin of the Association of Russian Geographers and Social Scientists. 2020;9:126-129.

34. Zharkova V. Modern Grand Solar Minimum will lead to terrestrial cooling. Temperature. 2020;7(3):217-222.
35. Reteyum A Yu. Epidemics in the setting of a large solar minimum. 1993.

36. Syvorotkin VL. The Montreal Protocol - the main scientific fiasco of the XXI century. Regnum October 26, 2020.

37. Roviello V, Roviello GN. Lower COVID-19 mortality in Italian forested areas suggests immunoprotection by Mediterranean plants. Environ Chem Letters. 2020;14.

38. Belashev BZ. Symbiosis with microbes. Features of the behavior of humans and animals System "Planet Earth»: 120 years since the birth and 75 years since the death of Yuri Vasilyevich Kondratyuk (Alexander Ignatievich Shargei). (1897-1942). M.: LENAND, 2017. p. 256-268. 